\title{
Facile isolation of a stable S6-symmetric methanol hexamer using the guest-free microporous metal-organic framework
}

DOI:

10.1515/zkri-2017-2090

\section{Document Version}

Final published version

Link to publication record in Manchester Research Explorer

Citation for published version (APA):

Jovial, S. A., Raftery, J., Anderson, M. W., \& Attfield, M. P. (2018). Facile isolation of a stable S -symmetric methanol hexamer using the guest-free microporous metal-organic framework: Zinc 5-tert-butyl 9 sophthalate. Zeitschrift fuer Kristallographie - Crystalline Materials, 1-7. https://doi.org/10.1515/zkri-2017-2090

Published in:

Zeitschrift fuer Kristallographie - Crystalline Materials

\section{Citing this paper}

Please note that where the full-text provided on Manchester Research Explorer is the Author Accepted Manuscript or Proof version this may differ from the final Published version. If citing, it is advised that you check and use the publisher's definitive version.

\section{General rights}

Copyright and moral rights for the publications made accessible in the Research Explorer are retained by the authors and/or other copyright owners and it is a condition of accessing publications that users recognise and abide by the legal requirements associated with these rights.

\section{Takedown policy}

If you believe that this document breaches copyright please refer to the University of Manchester's Takedown Procedures [http://man.ac.uk/04Y6Bo] or contact uml.scholarlycommunications@manchester.ac.uk providing relevant details, so we can investigate your claim.

\section{OPEN ACCESS}




\section{Samaila A. Jovial, James Raftery, Michael W. Anderson and Martin P. Attfield*}

\section{Facile isolation of a stable $\mathbf{S}_{6}$-symmetric methanol hexamer using the guest-free microporous metal- organic framework: zinc 5-tert-butyl isophthalate}

https://doi.org/10.1515/zkri-2017-2090

Received July 26, 2017; accepted December 22, 2017; published online January 19, 2018

Abstract: The ordered structure of the guest-free microporous metal-organic framework zinc 5-tert-butyl isophthalate $\left\{\mathrm{Zn}\left[\left(\mathrm{CH}_{3}\right)_{3} \mathrm{CC}_{6} \mathrm{H}_{3}\left(\mathrm{CO}_{2}\right)_{2}\right]\right\}$ has been determined and shown to be easily loaded with methanol to form $\left\{\mathrm{Zn}\left[\left(\mathrm{CH}_{3}\right)_{3}\right.\right.$ $\left.\left.\mathrm{CC}_{6} \mathrm{H}_{3}\left(\mathrm{CO}_{2}\right)_{2}\right]\right\} \cdot \mathrm{CH}_{3} \mathrm{OH}$. The methanol forms a $\mathrm{S}_{6}$-symmetric hexamer within the pores of the material that is uniquely defined by the void space and exerts a subtle structural effect on the framework structure of the host. The work demonstrates the use of this type of metal-organic framework as a matrix to isolate unique molecular clusters in a facile manner.

Keywords: adsorption; cluster compounds; matrix isolation; metal-organic frameworks; structure elucidation.

\section{Introduction}

Porous metal-organic frameworks (MOFs) are a class of crystalline nanoporous material composed of metal ions, or metal-containing inorganic clusters, linked by heteroatom-containing organic linker molecules to form 3-dimensional frameworks containing a 1-, 2-, or 3-dimensional channel system [1]. The framework in combination with the void volume of these materials bestows upon them a diverse array of interesting properties and potential applications [2]. One aspect of MOFs that has enabled their properties and potential applications to be fully understood is the ability to grow many of these materials

*Corresponding author: Dr. Martin P. Attfield, Centre for Nanoporous Materials, The University of Manchester, Brunswick Street, Manchester, M13 9PL, UK, E-mail: m.attfield@manchester.ac.uk; and School of Chemistry, The University of Manchester, Brunswick Street, Manchester, M13 9PL, UK

Samaila A. Jovial and Michael W. Anderson: Centre for Nanoporous Materials, The University of Manchester, Brunswick Street, Manchester, M13 9PL, UK; and School of Chemistry, The University of Manchester, Brunswick Street, Manchester, M13 9PL, UK James Raftery: School of Chemistry, The University of Manchester, Brunswick Street, Manchester, M13 9PL, UK in single crystal form that allows for accurate structure determination to understand what is occurring within the MOF during these processes or applications.

The absorption of methanol within porous MOFs is of great interest in a variety of separation processes, for example the removal of methanol from water or methanol from dimethyl ether [3-6], and as a potential working fluid in adsorption-driven heat pumps and chillers [7]. Such interest has led to the methanol adsorption/desorption isotherms being reported for numerous desolvated MOFs but much less structural work has been reported for such systems. Overall changes in unit cell parameters of the MOF have been reported during methanol adsorption/ desorption [8-10], but relatively few crystal structures have been reported for MOFs at various stages of methanol sorption processes [11].

The adsorption of the methanol by a porous MOF also acts simultaneously as a method to isolate oligomeric methanol species within the MOF [11], the nature of which depend on the framework characteristics of the MOF, for instance the presence of open metal sites when desolvated, the spatial arrangement of specific functional groups of the organic linker or the overall geometry of the void volume. The formation and isolation of such methanol structures is of great interest to the general scientific community in that many of these oligomers are regarded as bridging the states of matter gap between single molecular species that exist in the gas phase and the supramolecular oligomers that exist in the vapor, liquid or solid phase. Structural information on such oligomers and the intermolecular forces that bind them together are vital to understand important physical processes, for example nucleation processes, and other physicochemical properties of molecular systems in the different states of matter $[12,13]$.

Information on many methanol oligomers has been obtained by a variety of spectroscopic methods [12, 14], but crystallography yields more definitive information if the oligomers can be isolated in the solid state [15-17]. This has been achieved in some cases by isolating methanol oligomers during the crystallization of various materials [15, 16], including porous MOFs [18, 19], or by solvent exchanging [20, 21], or adsorbing [11] methanol into 
porous materials. All these oligomer formation methods are relatively laborious and can involve various time consuming, crystallization, solvent exchange, heating or evacuation stages. A possible route to simplify isolation of methanol oligomers is to use a guest-free microporous metal organic framework (GFMMOF) which is a member of a relatively small subset of MOFs that is unusual in that they crystallize without any non-framework species remaining in the void volume of the as synthesized MOF $[6,22]$. Simple addition of methanol to a suitable GFMMOF would be expected to be a facile rapid method to isolate and investigate methanol oligomers within the pore structure of the GFMMOF.

In this work, we use the previously reported GFMMOF zinc 5-tert-butyl isophthalate [Zn(tbip) tbip $=5$-tert-butyl isophthalate] [6] to isolate and characterize a $\mathrm{S}_{6}$-symmetric methanol hexamer in a facile single step process and determine the subtle structural effect of this methanol hexamer on the framework structure of the GFMMOF.

\section{Experimental section}

\section{Synthesis and preliminary characterization}

Zn(tbip) (1) was synthesized using the procedure of Li et al. [6]: zinc (II) nitrate hexahydrate (Sigma-Aldrich, 98\%; $98.5 \mathrm{mg}$ ) and $\mathrm{H}_{2}$ tbip (Sigma-Aldrich, 98\%; $74 \mathrm{mg}$ ) were dissolved in a mixture of deionized water $(6.5 \mathrm{~mL}$ ) and ethylene glycol (Sigma-Aldrich, $\geq 99 \%$; $1.5 \mathrm{~mL}$ ). The reagent mixture was placed in a $20 \mathrm{~mL}$ Teflon-lined steel autoclave and heated in an oven at $453 \mathrm{~K}$ for $84 \mathrm{~h}$ and slowly cooled in air to room temperature. The resultant solid product was separated by suction filtration and washed with de-ionized water and ethanol to yield brown columnar crystals of $\mathbf{1}$. The crystals were dried in air at room temperature.

Methanol containing crystals of $\mathbf{1}(\mathbf{1} \cdot \mathbf{M e O H})$ were obtained by simply soaking as synthesized crystals of $\mathbf{1}$ in methanol (SigmaAldrich, $\geq 99.9 \%$ ) before being extracted, placed in Fomblin ${ }^{\circledR}$ oil and mounted on the single crystal X-ray diffractometer.

Phase identification and sample purity of the product crystals were confirmed using a PANalytical X'Pert X-ray diffractometer. Powder X-ray diffraction (PXRD) patterns were obtained from ground samples using $\mathrm{Cu}-\mathrm{K} \alpha$ radiation at $40 \mathrm{kV}$ and $30 \mathrm{~mA}$, in the $2 \theta^{\circ}$ range 3-60 (with a $2 \theta^{\circ}$ step size of 0.017 and scan step time of $66 \mathrm{~s}$ ) whilst spinning. Thermogravimetric analysis (TGA) data were collected on the crystals using a Perkin-Elmer system. The sample was contained in a platinum holder and heated under a flow of nitrogen from room temperature to $873 \mathrm{~K}$ at a heating rate of $10^{\circ} \mathrm{C} \mathrm{min}^{-1}$.

\section{Single crystal X-ray diffraction}

Single-crystal X-ray data were collected [Cu K $\alpha$ radiation at 100(2) K] from a brown, columnar single crystal of $\mathbf{1}$ or $\mathbf{1} \cdot \mathbf{M e O H}$ mounted on a Bruker Apex-II CCD diffractometer. Determination of the unit cell dimensions of 1 revealed that the $c$-axis was double that reported for the original structure (1-original) [6]. The systematic absences were found to be consistent with the space group $R \overline{3} c$ after indexing the data using this unit cell as opposed to the space group $R \overline{3} m$ that was used in the structure refinement of 1-original [6]. Determination of the unit cell of $\mathbf{1} \cdot \mathbf{M e O H}$ revealed that it was similar to that reported for 1-original [6]. However, the space group that gave the best structure refinement with particular regard to the $t$-butyl groups was the lower symmetry space group $R \overline{3}$.

The structures of both compounds were solved by direct methods using SHELXS-97 and refined by full-matrix least squares using SHELXL-2016/6 [23, 24]. The Zn, O and some $\mathrm{C}$ atom positions were determined directly from the structure solution and the remaining $\mathrm{C}$ atoms were located subsequently from difference Fourier maps. The atomic displacement parameters of all of non- $\mathrm{H}$ atoms were refined anisotropically. The site occupancies of the methyl $\mathrm{C}$ atoms of the disordered $t$-butyl groups in $\mathbf{1} \cdot \mathbf{M e O H}$ were refined within the constraint that their total occupancy was unity. All the $\mathrm{H}$ atoms were geometrically placed and refined in riding mode with their isotropic atomic displacement factors fixed at values of 1.2 times $U_{e q}$ of the C atom to which they were directly connected, except for the $\mathrm{H}$ atoms of the methyl groups which were fixed at 1.5 times. The hydroxyl $\mathrm{H}$ atom of the methanol molecule in $\mathbf{1} \cdot \mathbf{M e O H}$ was excluded from the refined structure as it could not be refined to a sensible position as there was no convincing residual electron density for it and its proximity to more than one suitable hydrogen bond acceptor $\mathrm{O}$ atom made its geometric placement ambiguous; it is likely this atom is disordered around the $\mathrm{O}_{6}$ ring. The crystallographic data and structure refinement parameters for structures $\mathbf{1}$ and $\mathbf{1} \cdot \mathbf{M e O H}$ are given in Table 1.

Tab. 1: Crystallographic data and structure refinement parameters for $\mathbf{1}$ and $\mathbf{1} \cdot \mathbf{M e O H}$.

\begin{tabular}{lll}
\hline & $\mathbf{1}$ & $\mathbf{1} \cdot \mathrm{MeOH}$ \\
\hline Empirical formula & $\mathrm{C}_{12} \mathrm{H}_{12} \mathrm{O}_{4} \mathrm{Zn}$ & $\mathrm{C}_{13} \mathrm{H}_{16} \mathrm{O} \mathrm{Z}_{5} \mathrm{Zn}$ \\
$a=b(\AA)$ & $28.8574(11)$ & $28.9244(11)$ \\
$c(\AA)$ & $15.8751(6)$ & $8.1008(3)$ \\
$V\left(\AA^{3}\right)$ & $11,448.8(8)$ & $5869.3(5)$ \\
$Z$ & 36 & 18 \\
$\rho_{\text {calc }}\left(\mathrm{mg} \mathrm{m}^{-3}\right)$ & 1.491 & 1.618 \\
Crystal system & Trigonal & Trigonal \\
Space group & $R \overline{3} \mathrm{C}$ & $R \overline{3}$ \\
Crystal size $(\mathrm{mm})$ & $0.10 \times 0.16 \times 0.28$ & $0.11 \times 0.18 \times 0.26$ \\
$\Theta$ range $\left({ }^{\circ}\right)$ & $3.1-72.4$ & $3.1-71.3$ \\
Reflections collected/ & $10,167 / 2518$ & $5930 / 2500$ \\
unique $[\mathrm{I} \geq 2 \sigma(\mathrm{I})]$ & & \\
Linear absorption & 2.702 & 2.757 \\
coefficient $\left(\mathrm{mm} \mathrm{m}^{-1}\right)$ & & \\
Final $\mathrm{R}$ indices $[\mathrm{I} \geq 2 \sigma(\mathrm{I})]$ & $\mathrm{R} 1=0.028$ & $\mathrm{R} 1=0.059$ \\
& $\mathrm{wR} 2=0.082$ & $\mathrm{wR} 2=0.157$ \\
$\mathrm{R}$ indices (all data) & $\mathrm{R} 1=0.031$ & $\mathrm{R} 1=0.062$ \\
& $\mathrm{wR} 2=0.084$ & $\mathrm{wR} 2=0.158$ \\
\hline
\end{tabular}

${ }^{a}$ Crystallographic data, including structure factors, for the structures reported in this paper have been deposited with the Cambridge Crystallographic Data Centre as supplementary publication no. CCDC-1502788-1502789. Copies of the data can be obtained free of charge on application to CCDC, 12 Union Road, Cambridge CB2 1EZ, UK [Fax.: +44-1223/336-033; e-mail: deposit@ccdc.cam.ac.uk]. 


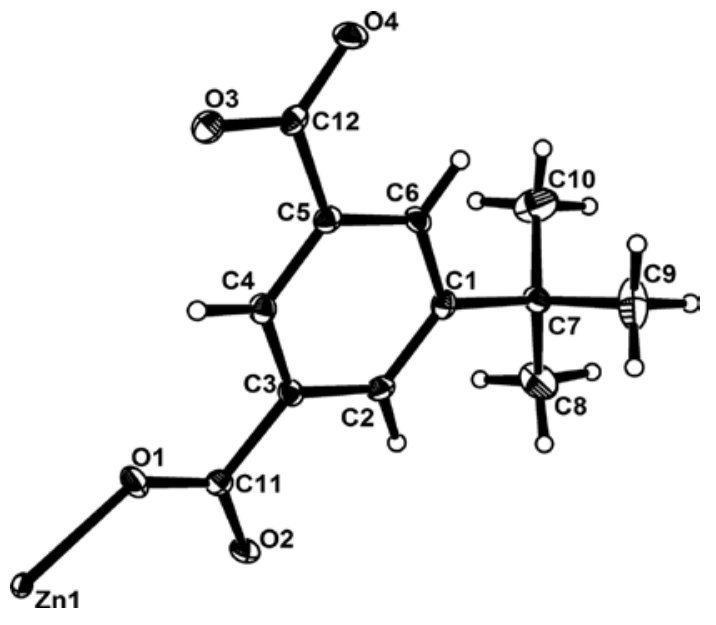

Fig. 1: The asymmetric unit of 1 . Non-hydrogen displacement ellipsoids are shown at the $70 \%$ probability level.

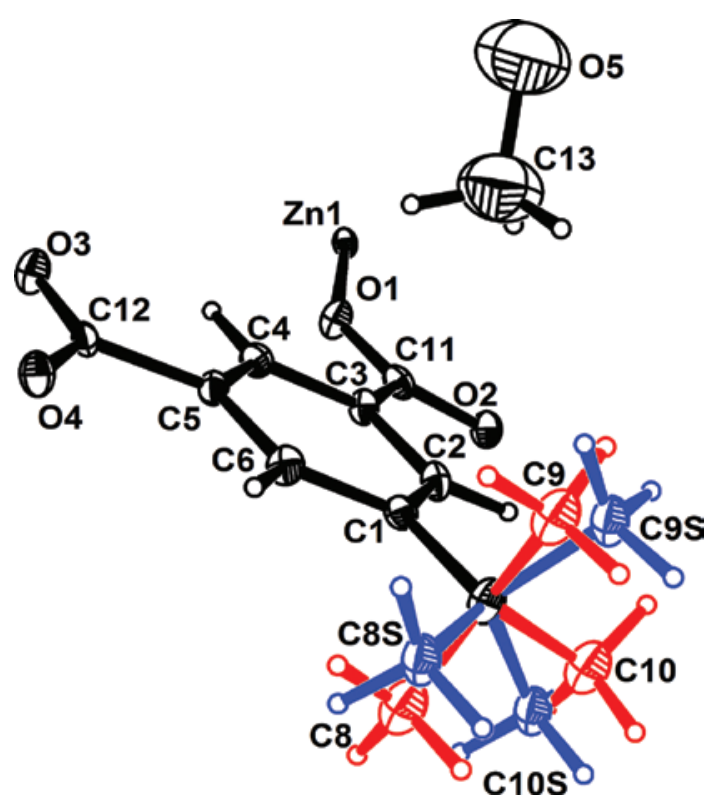

Fig. 2: The asymmetric unit of $\mathbf{1} \cdot \mathbf{M e O H}$ with the two different orientations of the $t$-butyl group shown by the blue and red shading of the atoms and bonds involved in the two different orientations. Non-hydrogen displacement ellipsoids are shown at the $50 \%$ probability level.

The asymmetric units of $\mathbf{1}$ and $\mathbf{1} \cdot \mathbf{M e O H}$ are shown in Figures 1 and 2, respectively.

\section{Results and discussion}

The powder X-ray diffraction pattern of $\mathbf{1}$ is shown in Figure S1 and was judged to be monophasic from the excellent agreement between the experimental powder
X-ray diffraction pattern and the calculated reflection positions using the unit cell parameters of 1-original [6]. The crystal structure of $\mathbf{1}$ is similar to that of 1-original in that it comprises $\mathrm{Zn}^{2+}$ ions connected to one another by the carboxylate groups of the tbip linkers to form a framework containing 1-dimensional channels running parallel to the $c$-axis as shown in Figure 3. The $\mathrm{Zn}^{2+}$ ions are tetrahedrally coordinated by $\mathrm{O}$ atoms from four different tbip ions to form a $3_{1}$ helical chain with a pitch for the $\mathrm{Zn}^{2+}$ ions of $7.93 \AA$ along the $c$-axis. Each chain is connected to three other identical chains through the tbip ions to form the framework structure of 1 that also contains strong $\pi-\pi$ interactions between the phenyl rings in the pairs of tbip ions found within the walls of the 1-dimensional channels of the framework. The pairs of phenyl rings involved in the $\pi-\pi$ interactions exhibit an off center parallel stacking arrangement [25] with a ring center of gravity distance of 3.5630(11) $\AA$ and a perpendicular distance between ring centers of gravity of 3.2373(7) $\AA$. The major difference between the structure of $\mathbf{1}$ and 1-original concerns the $t$-butyl groups of the tbip ions that are directed towards the center of the channels. These $t$-butyl groups are disordered over two orientations in 1-original. In the crystal structure of $\mathbf{1}$ it is found that these $t$-butyl groups are ordered resulting in a doubling of the $c$-axis to that reported for 1-original and adoption of space group $R \overline{3} c$ which is a maximal non-isomorphic subgroup of space group $R \overline{3} m$. The methyl groups of the $t$-butyl groups whose central $\mathrm{C}-\mathrm{C}$ bonds are directly aligned with each other along the [001] direction are found to adopt two different rotational orientations within the pores as shown in Figures 3 and 4. The reason for the difference in structures of $\mathbf{1}$ and 1-original may result from the different temperatures, $100 \mathrm{~K}$ and $293 \mathrm{~K}$, respectively, at which the $\mathrm{X}$-ray data were collected. The lower temperature at which the data for $\mathbf{1}$ were collected would allow subtle changes in the weak $\mathrm{C}-\mathrm{H} \cdots \mathrm{H}-\mathrm{C}$ or $\mathrm{C}-\mathrm{H} \cdots \mathrm{O}$ interactions, exemplified by the shortest $\mathrm{C}-\mathrm{H} \cdots \mathrm{O}$ interaction of $\mathrm{C} 10 \cdots \mathrm{O} 2$ 3.407 (2) $\AA$, to occur to optimize the orientation of the $t$-butyl groups in the lowest energy configuration possible and make it less likely for the $t$-butyl groups to overcome the activation energy barrier for rotation.

The guest-free nature of as synthesized Zn(tbip) was confirmed for $\mathbf{1}$ as no significant residual electron density was located within the pores of the structure and the TGA analysis displayed no mass loss before the decomposition of the tbip ligands at $\sim 425^{\circ} \mathrm{C}$ as previously reported and shown in Figure S2.

The crystal structure of $\mathbf{1} \cdot \mathbf{M e O H}$ is shown in Figure 5. Again the framework of the material is the same in terms of the $\mathrm{Zn}^{2+}$ ion coordination environment and metal 


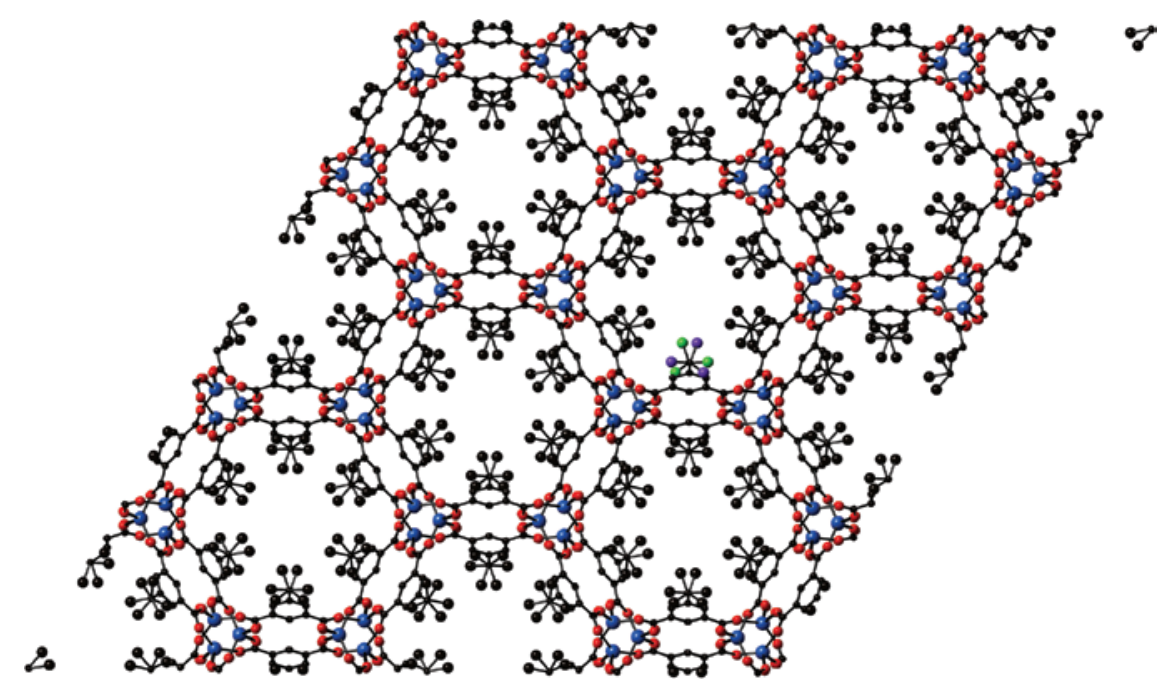

Fig. 3: A ball and stick representation of the structure of 1 viewed along the [001] direction. Atom colors: $\mathrm{Zn}$, blue; 0 , red; $\mathrm{C}$, black, $\mathrm{C}$ in one orientation of the $t$-butyl group, purple; $\mathrm{C}$ in the second orientation of the $t$-butyl group, green. All hydrogen atoms are omitted for clarity.

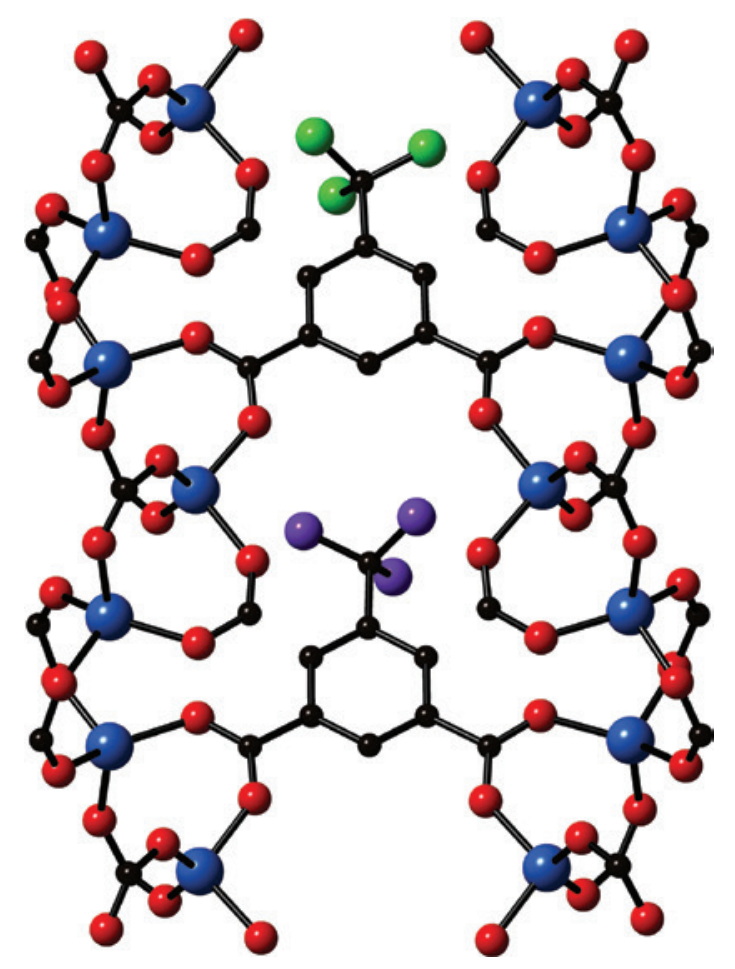

Fig. 4: A ball and stick representation of the structure of 1 viewed along the [1리이 direction. Atom colors: Zn, blue; O, red; C, black; C in one orientation of the $t$-butyl group, purple; $C$ in one orientation of the $t$-butyl group, green. All hydrogen atoms are omitted for clarity.

linker connectivity as in structure $\mathbf{1}$ and 1-original with strong $\pi-\pi$ interactions [ring center of gravity distance of 3.492(3) $\AA$ and a perpendicular distance between ring centers of gravity of 3.2488(18) $\AA$ ] between the phenyl rings in the pairs of tbip ions found within the walls of the framework. Within the channels of $\mathbf{1} \cdot \mathbf{M e O H}$ are located isolated $\mathrm{S}_{6}$-symmetric chair-like methanol hexamers as shown in Figures 5 and 6 . The hexamers are held together by moderately strong hydrogen bonds between the hydrophilic hydroxyl groups $(0 \cdots 0$ 2.62(1) $\AA$ ) [26] and the hydrophobic methyl groups are directed to the exterior of the hexamer where they form multiple $\mathrm{C}-\mathrm{H} \cdots \mathrm{H}-\mathrm{C}$ interactions with the $t$-butyl groups of the tbip groups as shown in Figure 7. The formation of this methanol hexamer structure allows for segregation of hydrophobic and hydrophilic interactions that stabilize the cluster within the void space of the GFMMOF.

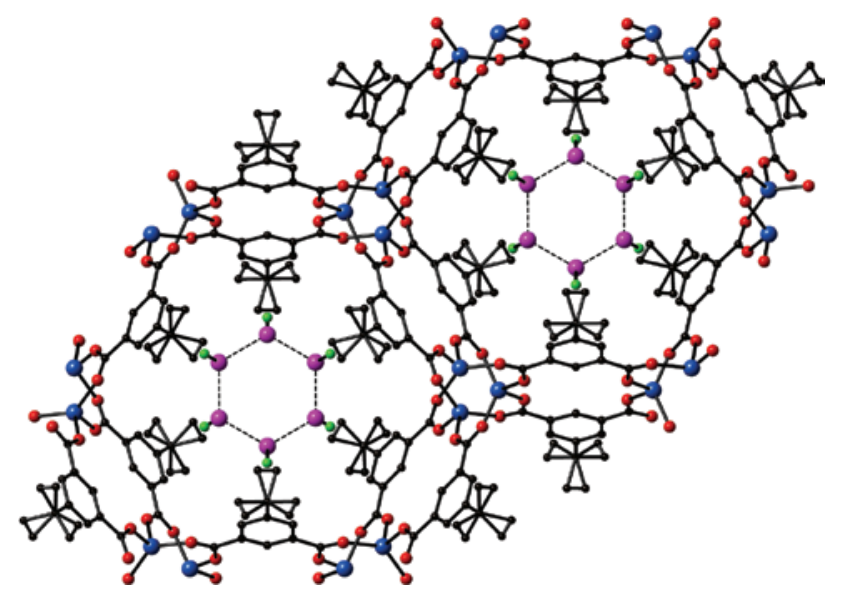

Fig. 5: A ball and stick representation of the structure of 1 $\cdot \mathrm{MeOH}$ viewed along the [001] direction. Atom colors: $\mathrm{Zn}$, blue; $\mathrm{O}$, red; $\mathrm{O}$ of $\mathrm{MeOH}$, magenta; $\mathrm{C}$, black; $\mathrm{C}$ of $\mathrm{MeOH}$, green. Dashed lines represent $0 \ldots 0$ hydrogen bonding interactions. All hydrogen atoms are omitted for clarity. 


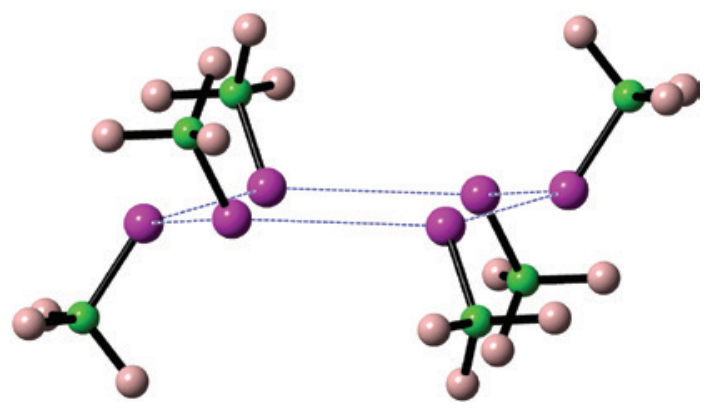

Fig. 6: A ball and stick representation of the structure of S6 methanol hexamer in the pores of $1 \cdot \mathrm{MeOH}$. Atom colors: 0 , magenta; $\mathrm{C}$, green; $\mathrm{H}$, pale salmon. Dashed lines represent $0 \cdots 0$ hydrogen bonding interactions.

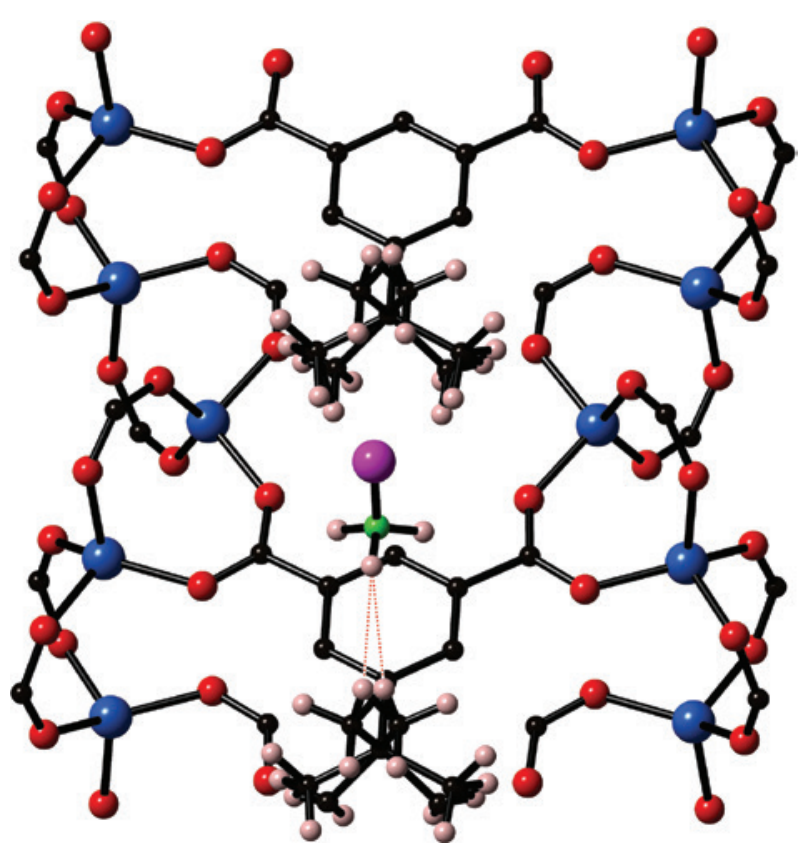

Fig. 7: A ball and stick representation of the structure of $1 \cdot \mathrm{MeOH}$ viewed along the $[\overline{1} 20]$ direction. Atom colors: $\mathrm{Zn}$, blue; 0 , red; 0 of $\mathrm{MeOH}$, magenta; $\mathrm{C}$, black; $\mathrm{C}$ of $\mathrm{MeOH}$, green; $\mathrm{H}$, pale salmon. Dashed lines represent closest $\mathrm{C}-\mathrm{H} \cdots \mathrm{H}-\mathrm{C}$ interactions. All hydrogen atoms are omitted for clarity except those of the methyl groups.

The $\mathrm{S}_{6}$-symmetric methanol hexamer, depicted by Pauling in 1962 [27], was proposed to be the major species in liquid methanol [28] and was first characterized fully using single crystal X-ray diffraction by Weyhermüller and Wieghardt [15]. Such hexamers have subsequently been isolated in $>10$ non-polymeric materials and the MOF, MAF-2 Cu(etz) (Hetz - 3,5-diethyl-1,2,4-triazole) [11]. Although, the structure of the methanol hexamer in $\mathbf{1} \cdot \mathbf{M e O H}$ can be described as "chair-like", the $\mathrm{O}$ atoms of the six methanol molecules are closer to being planar displaying an out of the chair plane angle of $12.8^{\circ}$. This contrasts to that observed for the hexamer in MAF-2 that displays a much larger out of the chair plane angle of $50.6^{\circ}$. It is noticeable that the void volume and framework of the MOF are vital in determining the structure of the methanol hexamer and that the specific geometry of the oligomer is determined, and may possibly be designed, by the pore space of the MOF.

The crystal structure of $\mathbf{1} \cdot \mathbf{M e O H}$ indicates that methanol is readily adsorbed into $\mathbf{1}$ by capillary condensation to form $\mathrm{Zn}$ (tbip) $\cdot \mathrm{MeOH}$ and so adsorbing $112 \mathrm{mg} \mathrm{g}^{-1}$ which is in excellent agreement with observed amount of $110 \mathrm{mg} \mathrm{g}^{-1}$ adsorbed after capillary condensation at $24.5^{\circ} \mathrm{C}$ and 90 Torr $\mathrm{MeOH}\left(\mathrm{P} / \mathrm{P}_{0}=0.73\right)[6]$. The isosteric heat of adsorption of methanol calculated from the reported adsorption isotherms at $60 \mathrm{mg} \mathrm{g}^{-1}$ methanol loading was $51 \mathrm{~kJ} \mathrm{~mol}^{-1}$ and was believed to include substantial adsorbate-adsorbate contributions [6]. This is confirmed by the structure of $\mathbf{1} \cdot \mathbf{M e O H}$ in which the hydrogen bonding within the methanol hexamer will be the strongest intermolecular interaction present within the system and so contribute considerably to the isosteric heat of adsorption.

The framework $t$-butyl groups of $\mathbf{1} \cdot \mathbf{M e O H}$ are found to be disordered over two nearly equally occupied orientations [orientation occupancies of 0.52(1) and 0.48(1)] in a similar manner to that found in 1-original resulting in the $c$ unit cell parameter being similar to that of 1-original and half that of $\mathbf{1}$. The adsorption of methanol into $\mathbf{1}$ results in this disorder presumably because of the strong interaction of the methyl $\mathrm{H}$ atoms of methanol (H13A) with $\mathrm{H}$ atoms (H9B, H9S1) of the $t$-butyl group in its two refined orientations, of length 2.29 and $2.30 \AA$ A respectively and as shown in Figure 7. This is the dominant interaction between the methanol and the $t$-butyl groups that is equally strong for either orientation of the $t$-butyl group and thus provides the impetus for the rotational orientation disorder of the $t$-butyl groups in $\mathbf{1} \cdot \mathbf{M e O H}$. Such an orientation determining interaction is not present in $\mathbf{1}$ causing other subtler interactions to influence the ordering of the $t$-butyl groups.

Formation of $\mathbf{1} \cdot \mathbf{M e O H}$ causes an overall expansion of the framework with unit cell parameter $a$ increasing by $0.2 \%$, unit cell parameter $c$ increasing by $2.1 \%$ and the unit cell volume increasing by $2.5 \%$ relative to the unit cell of $\mathbf{1}$. This indicates a certain amount of flexibility within the framework of $\mathbf{1}$, most noticeably in the [001] direction, to accommodate the size of the methanol hexamer within the framework's void volume that becomes greater than that found in $\mathbf{1}$. This behavior contrasts to the behavior MAF-2 upon methanol 
adsorption that results in an overall decrease in the unit cell volume [11].

\section{Conclusions}

The GFMMOF Zn(tbip) has been demonstrated to act as an ideal matrix to isolate $\mathrm{S}_{6}$-symmetric methanol hexamers within its pore space in a facile manner. The structure of the methanol hexamer is partially defined by the internal void space and chemical characteristics of the MOF so producing a unique structure of the hexamer in which the $\mathrm{O}$ atoms of the methanol molecules are arranged in a much more planar arrangement than that previously isolated in a MOF. The work demonstrates the potential of GFMMOFs to isolate structurally unique clusters of molecules in a facile manner for investigation of their properties and to better understand the sorption process within MOFs for future application.

\section{Supporting Information}

Powder X-ray diffraction and thermogravimetric data for 1 .

\section{References}

[1] G. Ferey, Hybrid porous solids: past, present, future. Chem. Soc. Rev. 2008, 37, 191.

[2] H.-C. Zhou, S. Kitagawa, Metal-organic frameworks (MOFs). Chem. Soc. Rev. 2014, 43, 5415.

[3] J. Y. Lee, D. H. Olson, L. Pan, T. J. Emge, J. Li, Microporous metalorganic frameworks with high gas sorption and separation capacity. Adv. Funct. Mater. 2007, 17, 1255.

[4] G. F. de Lima, A. Mavrandonakis, H. A. de Abreu, H. A. Duarte, T. Heine, Mechanism of alcohol-water separation in metal-organic frameworks. J. Phys. Chem. C 2013, 117, 4124.

[5] A. Shigematsu, T. Yamada, H. Kitagawa, Selective separation of water, methanol, and ethanol by a porous coordination polymer built with a flexible tetrahedral ligand. J. Am. Chem. Soc. 2012, 134, 13145.

[6] L. Pan, B. Parker, X.-Y. Huang, D. L. Olson, J. Y. Lee, J. Li, Zn(tbip) $\left(\mathrm{H}_{2}\right.$ tbip $=5$-tert-butyl isophthalic acid): a highly stable guestfree microporous metal organic framework with unique gas separation capability. J. Am. Chem. Soc. 2006, 128, 4180.

[7] M. F. de Lange, B. L. van Velzen, C. P. Ottevanger, K. J. F. M. Verouden, L.-C. Lin, T. J. H. Vlugt, J. Gascon, F. Kapteijn, Metal-organic frameworks in adsorption-driven heat pumps: the potential of alcohols as working fluids. Langmuir 2015, 31, 12783.

[8] R. I. Walton, A. S. Munn, N. Guillou, F. Millange, Uptake of liquid alcohols by the flexible Fe ${ }^{\text {III }}$ metal-organic framework MIL-53 observed by time-resolved in situ X-ray diffraction. Chem. Eur. J. 2011, 17, 7069.

[9] A. J. Fletcher, E. J. Cussen, D. Bradshaw, M. J. Rosseinsky, K. M. Thomas, Adsorption of gases and vapors on nanoporous $\mathrm{Ni}_{2}\left(4,42^{\prime} \text {-Bipyridine }\right)_{3}\left(\mathrm{NO}_{3}\right)_{4}$ metal-organic framework materials templated with methanol and ethanol: structural effects in adsorption kinetics. J. Am. Chem. Soc. 2004, 126, 9750.

[10] A. J. Fletcher, E. J. Cussen, T. J. Prior, M. J. Rosseinsky. C. J. Kepert, K. M. Thomas, Adsorption dynamics of gases and vapors on the nanoporous metal organic framework material $\mathrm{Ni}_{2}\left(4,4^{\prime} \text {-Bipyridine }\right)_{3}\left(\mathrm{NO}_{3}\right)_{4}$ : guest modification of host sorption behavior. J. Am. Chem. Soc. 2001, 123, 10001.

[11] J.-P. Zhang, X.-M. Chen, Exceptional framework flexibility and sorption behavior of a multifunctional porous cuprous triazolate framework. J. Am. Chem. Soc. 2008, 130, 6010.

[12] U. Buck, B. Schmidt, J. G. Siebers, Structural transitions and thermally averaged infrared spectra of small methanol clusters. J. Chem. Phys. 1993, 99, 9428.

[13] V. A. Durov, I. Y. Shilov, Simulation of the supramolecular organization and permittivity of methanol over a wide range of state parameters, including the supercritical region. Russ. J. Phys. Chem. 2008, 82, 1838.

[14] U. Buck, J. G. Siebers, R. J. Wheatley, Structure and vibrational spectra of methanol clusters from a new potential model. J. Chem. Phys. 1998, 108, 20.

[15] T. Weyhermüller, K. Wieghardt, The structure of the $\mathrm{S}_{6}$-symmetric methanol hexamer assembled in a supramolecular hydrophobic cavity. Chem. Commun. 1998, 557.

[16] L. Benisvy, I. Mutikainen, M. Quesada, U. Turpeinen, P. Gamez, J. Reedijk, The self-assembly between $\mathrm{C}_{2}$-symmetric (methanol) ${ }_{6}$ or $\mathrm{S}_{6}$-symmetric (ethanol) 6 cyclohexamers and paddlewheel dinuclear copper units leads to unique 1D polymer chains. Chem. Commun. 2006, 3723.

[17] A. H. Narten, A. Habenschuss, Hydrogen bonding in liquid methanol and ethanol determined by X-ray diffraction. J. Chem. Phys. 1984, 80, 3387.

[18] Z. Wang, V. C. Kravtsov, M. J. Zaworotko, Ternary nets formed by self-assembly of triangles, squares, and tetrahedra. Angew. Chem. Int. Ed. 2005, 44, 2877.

[19] S. Seth, P. Venugopalan, J. N. Moorthy, Porous coordination polymers of diverse topologies based on a twisted tetrapyridylbiaryl: application as nucleophilic catalysts for acetylation of phenols. Chem. Eur. J. 2015, 21, 2241.

[20] M.-H. Zeng, Y.-X. Tan, Y.-P. He, Z. Yin, Q. Chen, M. Kurmoo, A porous 4-fold-interpenetrated chiral framework exhibiting vapochromism, single-crystal-to-single-crystal solvent exchange, gas sorption, and a poisoning effect. Inorg. Chem. 2013, 52, 2353.

[21] Y.-S. Wei, K.-J Chen, P.-Q. Liao, B.-Y. Zhu, R.-B. Lin, H.-L. Zhou, B.-Y. Wang, W. Xue, J.-P. Zhang, X.-M. Chen, Turning on the flexibility of isoreticular porous coordination frameworks for drastically tunable framework breathing and thermal expansion. Chem. Sci. 2013, 4, 1539.

[22] L. Pan, D. H. Olson, L. R. Ciemnolonski, R.Heddy, J. Li, Separation of hydrocarbons with a microporous metal-organic framework. Angew. Chem. Int. Ed. 2006, 45, 616.

[23] G. M. Sheldrick, A short history of SHELX. Acta Crystallogr. A 2008, 64, 112. 
[24] G. M. Sheldrick, Crystal structure refinement with SHELXL. Acta Crystallogr. C 2015, 71, 3.

[25] C. R. Martinez, B. L. Iverson, Rethinking the term "pi-stacking". Chem. Sci. 2012, 3, 2191.

[26] G. A. Jeffrey, An Introduction to Hydrogen Bonding, Oxford University Press, Oxford, 1997.

[27] L. Pauling, The Nature of the Chemical Bond, Cornell University Press, Ithaca, NY, 1962.
[28] S. Sarkar, R. N. Joarder, Molecular clusters and correlations in liquid methanol at room temperature. J. Chem. Phys. 1993, 99, 2032.

Supplemental Material: The online version of this article offers supplementary material (https://doi.org/10.1515/zkri-2017-2090). 